\title{
Multivariate Parameter Optimization of PAM Wastewater Treatment by Ti/Ir-Ta Electrocatalysis via the Box-Behnken Design
}

\author{
Ruting Tian, Fanxiu Li, Yi Yang, Jian Huang, Mijia Zhu* \\ School of Chemistry and Environmental Engineering, Yangtze University, Jingzhou 434023, Hubei, P.R.China
}

Received: 6 May 2021

Accepted: 17 July 2021

\begin{abstract}
In this study, the electrocatalysis method is used to degrade polyacrylamide (PAM) from wastewater. This method can degrade PAM rapidly and effectively, and it has no secondary pollution but has clean and environmental protection. The Box-Behnken design of response surfaces is used to optimize the PAM degradation experiment of wastewater. In accordance with the regression analysis results, the second-order polynomial fitting model is significant. The best conditions for the experiment are a current density of $58.8 \mathrm{~mA} / \mathrm{cm}^{2}$, an electrode plate spacing of $3.07 \mathrm{~cm}$, initial $\mathrm{pH}$ of the solution of 6.73 and reaction time of $2.225 \mathrm{~h}$. The COD removal rate reaches $92.7 \%$, and the predicted value is 92.24\%. Therefore, electrocatalytic degradation of PAM has a good application prospect.
\end{abstract}

Keywords: electrocatalysis, PAM, Box-Behnken design, response surface method, COD removal efficiency

\section{Introduction}

Polyacrylamide (PAM) has the functions of flocculation, adhesion, resistance reduction and thickening. PAM is used not only in water treatment but also in printing and dyeing, papermaking and oil exploitation industries [1]. In the process of oilfield energy development, the injection of PAM solution can improve the oil-water velocity of flow ratio, increase the viscosity of driving fluid, reduce the permeability of formation water and improve oil recovery [2-3]. However, the discharge of water containing PAM to the environment will lead to many environmental problems

e-mail: zhumijia128@163.com and cause many health issues for human beings and potential harm to the ecosystem. The viscosity of wastewater containing PAM is relatively high, which increases the ability of the wastewater to carry suspended solids, thus making the suspended solids in water exceed the standard [4]. PAM is beneficial to the growth of sulphate-reducing bacteria in water and has a strong corrosive effect on water treatment facilities. Therefore, how to remove the residual PAM in wastewater effectively has become a key concern in the field of environment. At present, the main methods for treating polymer-containing wastewater are physical treatment [5], biodegradation [6-8], chemical degradation [9-10] and combination method [11]. The use of an electrochemical method for the degradation of wastewater is characterized by many advantages, including flexible operation, simple equipment, clean 
and environmental protection, no secondary pollution, fast degradation reaction speed, mild reaction conditions and evident degradation effect of PAM. Nevertheless, the effect of electrochemistry is influenced by electrode materials, operating conditions and other factors. Our team used an aluminium electrode to treat oilfield polymer wastewater [12]. Although good results have been achieved, the further promotion of this technology is limited due to the excessive consumption of electrode plate and secondary pollution in the electrochemical process. By contrast, the electrocatalysis technology uses an insoluble electrode as a material to carry out water treatment research, and the reaction is more thorough and does not produce secondary pollution [1314]. The purpose of high efficiency and environmental protection degradation of oilfield wastewater can be achieved through the optimisation and improvement research of plate material, current density, plate spacing, reaction time and other factors.

Electrocatalysis is a technology that has achieved good results in the research of organic wastewater, such as phenol [15] and dinitrobenzene [16]. Yang [17] also tried to use an insoluble electrode to degrade PAM wastewater for the first time. Compared with the common chemical flocculation and biodegradation technology, it has the characteristics of short time and high efficiency. However, no systematic study has been conducted on the related parameters. The conventional one-factor-at-a-time approach has been widely used to optimise the effects of various factors to attain the best system performance. This approach determines the influence of various factors on degradation rate, that is, whilst changing one of the factors, the other factors remain unchanged to study the influence of each factor in turn. Accordingly, this approach needs to conduct multibatch experiments, which is a time- and labourconsuming process. It fails to consider any possible interaction amongst the factors. The response surface methodology (RSM) evaluates the influencing factors and their interactions by establishing mathematical models and determines the best experimental parameters. The number of experiments is minimal. The objectives of this study are to optimise the experiment of electrocatalytic oxidation degradation of PAM by using RSM and obtain the maximum response value and corresponding experimental parameters from a mathematical model to realise enhanced experimental results.

\section{Experimental}

\section{Material}

The solvent used in the experiment is distilled water. In order to simulate PAM wastewater, sodium chloride is added to distilled water as electrolyte, and sodium hydroxide and hydrochloric acid solution are used to adjust the $\mathrm{pH}$ value. The reagents used are of analytical grade. The $\mathrm{pH}$ value is measured by $\mathrm{pH}$ meter, and the COD of the sample is determined by QCOD-2E rapid analyzer (Changhong Co., Ltd., Shenzhen, Guangdong). A $500 \mathrm{ppm}$ PAM solution was prepared by dissolving $0.50 \mathrm{~g}$ PAM in $1000 \mathrm{~mL}$ water. The average molecular weight of PAM was 5 million and the degree of hydrolysis was $27 \%$. Use $0-30 \mathrm{~V}$ DC regulated power supply (Hong Kong Longwei Instrument Co., Ltd.) for electrolysis.

\section{Experimental Methods}

The electrolysis experiment was conducted in a cylindrical glass cell. In this process, the anode was mainly titanium plate, and different elements were coated on the plate surface. The electrodes were $\mathrm{Ru}-\mathrm{Ir}$ and Ir-Ta (size: $10 \mathrm{~cm} \times 12 \mathrm{~cm}$; thickness: $0.2 \mathrm{~cm}$ ), and the cathode was Ti plate (size: $10 \mathrm{~cm} \times 12 \mathrm{~cm}$; thickness: $0.2 \mathrm{~cm})$. The electrolyte $(1000 \mathrm{~mL})$ was poured into the experimental electrolyser, and the electrodes were immersed in the electrolyte to achieve the required effective electrolysis area. The electrodes were connected to a DC-regulated power supply with a current range of 0-5 A and a voltage range of $0-30 \mathrm{~V}$ to provide current density. All experiments were performed at room temperature $\left(10^{\circ} \mathrm{C}\right)$, and the $\mathrm{COD}$ value was determined at the end of the experiment.

\section{Experimental Design}

The response surface method (RSM) was used for the experimental design, data analysis, and model construction. The aim was to investigate the relationship between COD removal efficiency and four operating parameters (i.e. current density, inter-electrode gap, $\mathrm{pH}$ and operation time). After further narrowing the range of experimental parameters, we selected the current density of $40-60 \mathrm{~mA} / \mathrm{cm}^{2}$, the plate spacing of $2-4 \mathrm{~cm}$, the $\mathrm{pH}$ of 6-8 and the reaction time of 1.5-2.5 h. The Box-Behnken design (BBD) was specifically selected as it was more efficient than other RSM designs when there are three or four variables [18]. The four selected process variables, current density, inter-electrode gap, $\mathrm{pH}$ and operation time, were defined as $X_{1}, X_{2}, X_{3}$ and $X_{4}$, respectively, COD removal efficiency were defined as $Y$. Each parameter was coded at three levels, -1 (minimum), 0 (central), and +1 (maximum), covering the entire study range. Table 1 shows the Box-Behnken design matrix. Analysis of variance (ANOVA) was used to analyze the experimental data. The adequacy of the developed models was measured by coefficient of determination $\left(R^{2}\right)$ and adjusted coefficient of determination $\left(R_{\text {adj }}^{2}\right)$ analyses. After fitting the models, the generated data were used for $3 \mathrm{D}$ response surface optimization. The statistical software Design Expert 8.0 (Stat-Ease Inc., Minneapolis, USA) was applied for the experiment design, analysis and optimisation.

A Box-Behnken design requires an experiment number according to $N=k^{2}+k+C_{p}$, where $k$ is the 
Table 1. Experimental range and levels of the independent variablesin Box-Behnken design.

\begin{tabular}{|c|c|c|c|c|}
\hline \multirow{2}{*}{ Variables, unit } & \multirow{2}{*}{ Factors } & \multicolumn{3}{|c|}{ Ranges and levels } \\
\cline { 3 - 5 } & & -1 & 0 & 1 \\
\hline Current density $\left(\mathrm{mA} / \mathrm{cm}^{2}\right)$ & $X_{1}$ & 40 & 50 & 60 \\
\hline Inter-electrode gap $(\mathrm{cm})$ & $X_{2}$ & 2 & 3 & 4 \\
\hline $\mathrm{pH}$ & $X_{3}$ & 6 & 7 & 8 \\
\hline Reaction time (h) & $X_{4}$ & 1.5 & 2 & 2.5 \\
\hline
\end{tabular}

factor number and $C_{p}$ is the replicate number of the central point. Experimental data from the Box-Behnken design can be analyzed and fitted to a second-order model using Design Expert 8.0 software and the following Equation (1):

$$
Y=\beta_{0}+\sum_{\mathrm{i}=1}^{\mathrm{k}} \beta_{\mathrm{i}} X_{\mathrm{i}}+\sum_{\mathrm{i}=1}^{\mathrm{j}-1} \sum_{\mathrm{j}=1}^{\mathrm{k}} \beta_{\mathrm{j}} X_{\mathrm{i}} X_{\mathrm{j}}+\sum_{\mathrm{i}=1}^{\mathrm{k}} \beta_{\mathrm{i}} X_{\mathrm{i}}^{2}+\mathrm{e}_{\mathrm{i}}
$$

...where $Y$ is COD removal efficiency, $\beta_{0}$ is a constant coefficient, $X_{i}$ and $X_{j}$ are variables, $\beta_{i}$ is the coefficient of response surface (linear term) that determines the influence of parameters on response surface, $\beta_{i j}$ refers to the effect of the interaction among variables $i$ and $j, \beta_{i i}$ is a parameter that determines the shape of the curve, $k$ is the number of studied factors, and $e_{i}$ is the error. The coding value of process parameters can be determined by the following formula (2):

$$
X_{\mathrm{i}}=\frac{\mathrm{x}_{\mathrm{i}}-\mathrm{x}_{0}}{\Delta \mathrm{x}_{\mathrm{i}}}
$$

In the above formula, $X_{i}$ is the dimensionless coded value of the $i$ th independent variable, $x_{i}$ is the uncoded value of the ith independent variable, $x_{0}$ is the uncoded independent variable of the center point, and $\Delta x_{i}$ is the step change value from low level $(-1)$ to high level $(+1)$.

\section{Results and Discussion}

\section{Effect of Anode Materials}

As shown in Fig. 1, with the prolongation of electrolysis time, the degradation effect of PAM by using the two electrodes changed, the concentration of PAM decreased, and the degradation rate increased. After $3 \mathrm{~h}$, the degradation rates of PAM were $80.54 \%$ and $88.19 \%$. When the initial concentration was $500 \mathrm{mg} / \mathrm{L}$, the current density was $30 \mathrm{~mA} / \mathrm{cm}^{2}$, the electrode spacing was $3 \mathrm{~cm}$, and the electrolyte concentration was $5000 \mathrm{mg} / \mathrm{L}$. The degradation rate of the $\mathrm{Ru}-\mathrm{Ir}$ electrode was $80.54 \%$, and the degradation

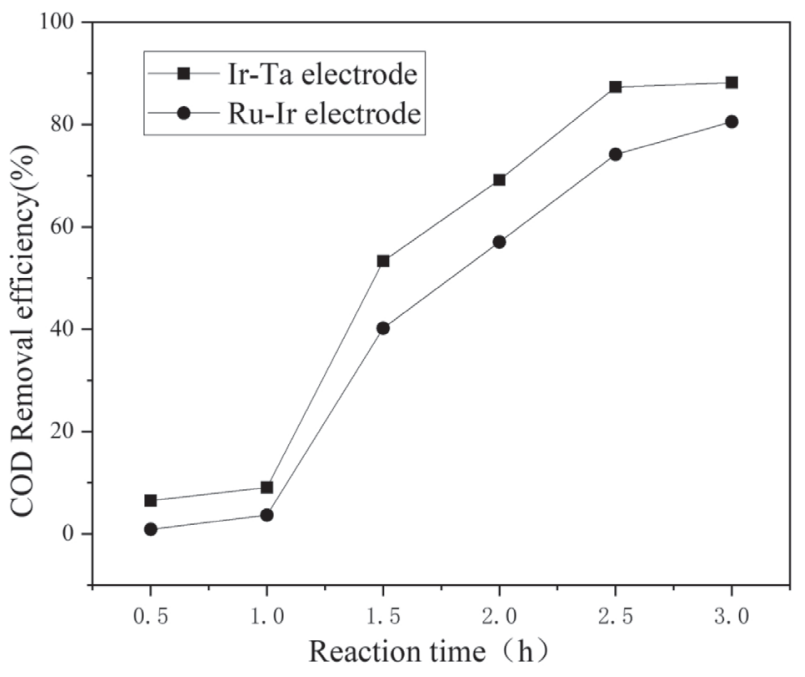

Fig. 1. Effect of two different electrodes on COD removal efficiency.

rate of the Ir-Ta electrode PAM was $88.19 \%$ after $3 \mathrm{~h}$ of electrolysis. The effect of the Ir-Ta electrode was better at any time of electrolysis. In the electrolysis process, the electrolyte solution could invade into the electrodes through the surface cracks, such that the electrode plates were slowly oxidised; in particular, the $\mathrm{Ru}-\mathrm{Ir}$ electrode plate was corroded, thus affecting the electrolysis effect of the electrode [19]. Hwang [20] determined that $\mathrm{Ta}$ is an inert oxide. Doping Ta oxide in an electrode can improve the durability and stability of Ir, delay the loss of the electrode under acidic conditions and enhance the ability of the anode to resist oxygen passivation. The results showed that the degradation rate of PAM was higher when the Ir-Ta electrode was used as anode but lower when the $\mathrm{Ru}-\mathrm{Ir}$ anode was used as anode. Therefore, in the next experiment, the Ir-Ta electrode were chose as anode to study the best reaction conditions.

\section{Effect of Current Density}

The degradation efficiency of PAM is related to the electron transfer capability and generation capability of $\cdot \mathrm{OH}$ and other active free radicals. The electron transfer capability and generation capability of free radicals depend on the applied current density [21]. The higher the current density is, the more charge transfer in the solution will be, that is, the stronger the electron transfer capability will be, and the faster the electrode reaction rate will be. When the current density increases, the electrode potential of the anode increases, the electrode reaction rate accelerates, and substantial active substances, such as $\cdot \mathrm{OH}$ radicals, are produced per unit time. The reaction with PAM accelerates, the concentration of PAM decreases, and the degradation rate of PAM increases. However, excessive current will also increase the energy consumption of the experimental system. This condition will present 


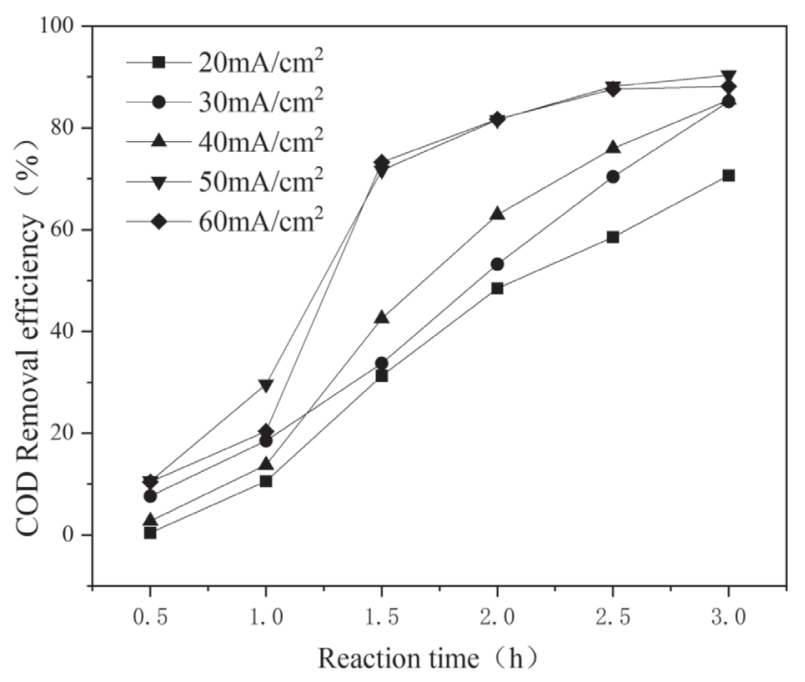

Fig. 2. Effect of current density on COD removal efficiency.

electrolytic water and other side reactions, thus reducing the current efficiency of electrocatalytic oxidation. In Arwa Abdelhay's experiment, the increase in the applied current density from $1.28 \mathrm{~mA} / \mathrm{cm}^{2}$ to $2.55 \mathrm{~mA} / \mathrm{cm}^{2}$ enhanced the COD removal efficiency. When the current density was further increased from $2.55 \mathrm{~mA} / \mathrm{cm}^{2}$ to $3.83 \mathrm{~mA} / \mathrm{cm}^{2}$, no significant increase in COD removal efficiency occurred. Calculation indicated that when the current density was $1.28 \mathrm{~mA} / \mathrm{cm}^{2}$, COD in the solution could be removed at the minimum cost [22]. Therefore, the current densities of 20, 30, 40, 50 and $60 \mathrm{~mA} / \mathrm{cm}^{2}$ were designed. In accordance with Fig. 2, when the current density reached $50 \mathrm{~mA} / \mathrm{cm}^{2}$, the degradation rate of PAM increased slowly, and the trend was unobvious. When the current density was $50 \mathrm{~mA} / \mathrm{cm}^{2}$, the degradation rate of PAM was $90.36 \%$.

\section{Effect of Inter-Electrode Gap}

The distance between the two electrodes would affect the electric field strength of the solution, which will affect the degradation rate of PAM. When the plate spacing decreased, the electric field intensity and current density, the force between the electrodes and the conductivity increased. As a result, the mass transfer effect of the solution was increased, the migration rate of charged ions was accelerated, and the generation capability of active free radicals (such as $\cdot \mathrm{OH}$ and $\mathrm{O}^{2-}$ ) in the solution was enhanced; the reaction with PAM accelerated, thus improving the removal efficiency of COD in water [23]. Nonetheless, an excessively small inter-electrode gap is unconducive to the electrochemical catalytic oxidation reaction because the solution between the two plates is difficult to flow and exchange with the solution outside the plate. This condition will lead to uneven solution mixing, resulting in a concentration difference and a waste of electric energy. Therefore, in this experiment, the inter-electrode gap was adjusted from $1 \mathrm{~cm}$ to $5 \mathrm{~cm}$.

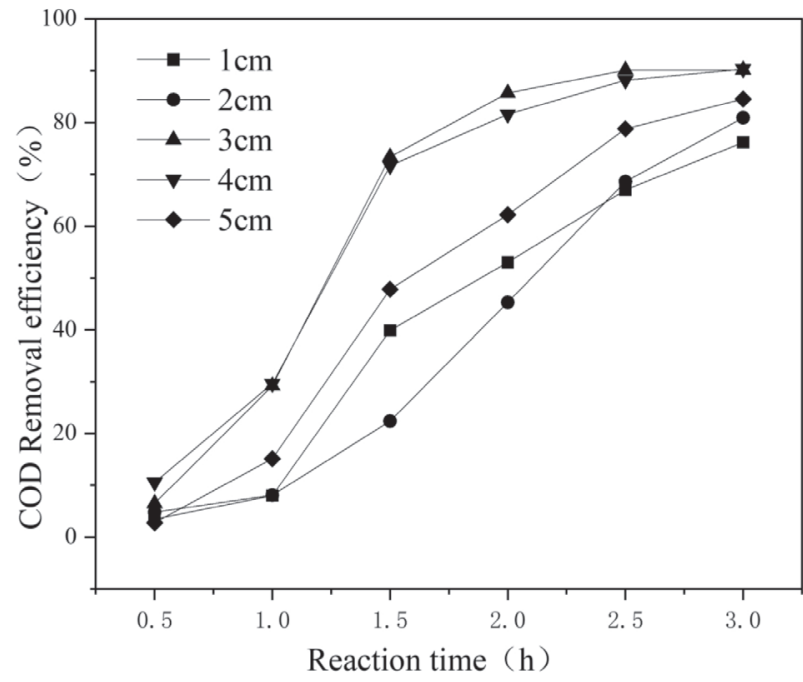

Fig. 3. Effect of inter-electrode gap on COD removal efficiency.

The other operating parameters were as follows: current density $=30 \mathrm{~mA} / \mathrm{cm}^{2}$, electrolyte concentration and initial $\mathrm{pH}=7$. As shown in Fig. 3, with the increase in plate spacing, the COD removal efficiency firstly increased and then decreased. The degradation rates of PAM at 1, 2, 3, 4 and $5 \mathrm{~cm}$ were $76.20 \%, 80.95 \%$, $90.21 \%, 90.36 \%$ and $84.57 \%$, respectively. When the inter-electrode gap was $3 \mathrm{~cm}$, the degradation rate of PAM reached the maximum, that is, $3 \mathrm{~cm}$ was the best inter-electrode gap. In the subsequent experiments, the inter-electrode gap of $3 \mathrm{~cm}$ was selected as an optimum reaction condition.

\section{Effect of $\mathrm{pH}$}

In Fig. 4, the degradation rate of PAM firstly increased and then decreased with the increase in $\mathrm{pH}$. Moreover, the degradation rate of PAM under acidic conditions was significantly higher than that under

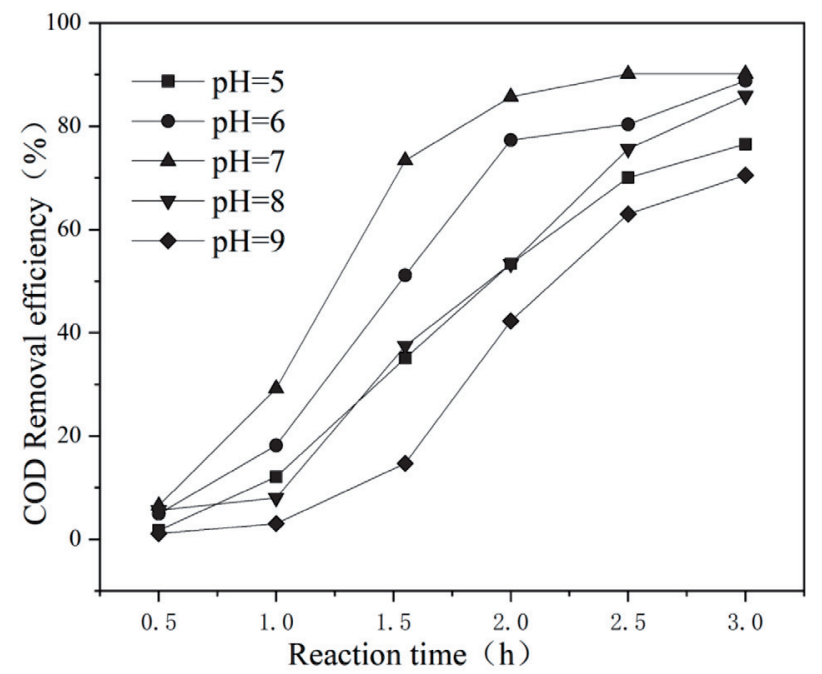

Fig. 4. Effect of $\mathrm{pH}$ on COD removal efficiency. 
Table 2. Design matrix in coded units and the experimental responses.

\begin{tabular}{|c|c|c|c|c|c|}
\hline Rum number & Current density $\left(X_{1}\right)$ & Inter-electrode gap $\left(X_{2}\right)$ & $\mathrm{pH}\left(X_{3}\right)$ & Reaction time $\left(X_{4}\right)$ & COD Removal efficiency $(Y, \%)$ \\
\hline 1 & 0 & 0 & -1 & 1 & 80.40 \\
\hline 2 & -1 & 0 & 0 & -1 & 69.20 \\
\hline 3 & -1 & -1 & 0 & 0 & 58.20 \\
\hline 4 & 0 & 0 & 0 & 0 & 85.60 \\
\hline 5 & 1 & 0 & 1 & 0 & 52.34 \\
\hline 6 & 0 & 0 & 1 & 1 & 54.17 \\
\hline 7 & 1 & 0 & 0 & 1 & 88.24 \\
\hline 8 & 0 & 0 & 0 & 0 & 83.00 \\
\hline 9 & 0 & 0 & -1 & -1 & 65.20 \\
\hline 10 & 1 & 0 & -1 & 0 & 74.30 \\
\hline 11 & 0 & 0 & 1 & -1 & 37.20 \\
\hline 12 & -1 & 0 & -1 & 0 & 50.20 \\
\hline 13 & 0 & -1 & -1 & 0 & 22.01 \\
\hline 14 & -1 & 0 & 0 & 1 & 70.98 \\
\hline 15 & 0 & 1 & 0 & -1 & 70.66 \\
\hline 16 & -1 & 1 & 0 & 0 & 59.93 \\
\hline 17 & 0 & -1 & 1 & 0 & 39.70 \\
\hline 18 & 0 & -1 & 0 & -1 & 25.50 \\
\hline 19 & 0 & 1 & -1 & 0 & 75.20 \\
\hline 20 & 0 & 1 & 1 & 0 & 49.34 \\
\hline 21 & 1 & 0 & 0 & -1 & 73.10 \\
\hline 22 & -1 & 0 & 1 & 0 & 44.30 \\
\hline 23 & 0 & 1 & 0 & 1 & 82.40 \\
\hline 24 & 1 & -1 & 0 & 0 & 45.80 \\
\hline 25 & 0 & 0 & 0 & 0 & 87.70 \\
\hline 26 & 0 & -1 & 0 & 1 & 83.40 \\
\hline 27 & 1 & 1 & 0 & 0 & 83.10 \\
\hline
\end{tabular}

alkaline conditions. Under acidic conditions, the acyl group of PAM in the solution was easy to be converted into a carboxyl group. Such conversion reduced the internal hydrogen bonding amongst molecules, thus increasing the solubility of PAM in water and facilitating the degradation of the solution. In alkaline conditions, the carboxyl group in the solution was hydrolysed to carboxylate ions, and the amide group in PAM combined with carboxylate ions to form a hydrogen bond easily. This phenomenon increased the stability of molecules and was unconducive to the degradation of PAM in the solution. Li et al. [24] found in an experiment of electrolytic petrochemical wastewater that a large amount of adsorbed $\cdot \mathrm{OH}$ was produced at low $\mathrm{pH}$, and the degradation performance would be reduced with the increase in $\mathrm{pH}$. In the experiment, $1 \mathrm{~L}$ of PAM solution with a concentration of $500 \mathrm{mg} / \mathrm{L}$ was used for electrolysis, the electrode spacing was $3 \mathrm{~cm}$, the electrolyte concentration was $5000 \mathrm{mg} / \mathrm{L}$, and the current density was $30 \mathrm{~mA} / \mathrm{cm}^{2}$. The degradation rates of PAM were $76.56 \%, 88.84 \%$, $90.21 \%, 85.91 \%$ and $70.52 \%$ when $\mathrm{pH}$ was adjusted to $5,6,7,8$ and 9, respectively, with $\mathrm{HCl}$ and $\mathrm{NaCl}$. Under alkaline conditions, the degradation rate of PAM was relatively low. Hence, when $\mathrm{pH}=7$, the degradation effect of PAM was highest, and the degradation rate was $90.21 \%$.

\section{ANOVA and Model Fitting}

Table 2 shows the experimental results for COD removal efficiency based on the Box-Behnken 
Table 3. ANOVA for response function $Y$ and variables selected to fit a model.

\begin{tabular}{|c|c|c|c|c|c|c|}
\hline Source & Sum of squares & $\mathrm{df}$ & Mean square & $F$-value & $\mathrm{p}$-value $\operatorname{Prob}>F$ & Remark \\
\hline Model & 8929.33 & 14 & 637.81 & 9.77 & 0.0002 & S \\
\hline$X_{1}$ & 342.08 & 1 & 342.08 & 5.24 & 0.0410 & $\mathrm{~S}$ \\
\hline$X_{2}$ & 1776.82 & 1 & 1776.82 & 27.22 & 0.0002 & $\mathrm{~S}$ \\
\hline$X_{3}$ & 678.91 & 1 & 678.91 & 10.40 & 0.0073 & $\mathrm{~S}$ \\
\hline$X_{4}$ & 1174.73 & 1 & 1174.73 & 18.00 & 0.0011 & $\mathrm{~S}$ \\
\hline$X_{1} X_{2}$ & 316.31 & 1 & 316.31 & 4.85 & 0.0480 & S \\
\hline$X_{1} X_{3}$ & 64.48 & 1 & 64.48 & 0.99 & 0.3399 & NS \\
\hline$X_{1} X_{4}$ & 44.62 & 1 & 44.62 & 0.68 & 0.4245 & NS \\
\hline$X_{2} X_{3}$ & 474.15 & 1 & 474.15 & 7.26 & 0.0195 & S \\
\hline$X_{2} X_{4}$ & 532.69 & 1 & 532.69 & 8.16 & 0.0144 & $\mathrm{~S}$ \\
\hline$X_{3} X_{4}$ & 0.78 & 1 & 0.78 & 0.012 & 0.9146 & NS \\
\hline$X_{1}^{2}$ & 270.75 & 1 & 270.75 & 4.15 & 0.0644 & NS \\
\hline$X_{2}^{2}$ & 1439.93 & 1 & 1439.93 & 22.06 & 0.0005 & $\mathrm{~S}$ \\
\hline$X_{3}^{2}$ & 2770.35 & 1 & 2770.35 & 42.45 & $<0.0001$ & $\mathrm{~S}$ \\
\hline$X_{4}^{2}$ & 57.38 & 1 & 57.38 & 0.88 & 0.3669 & NS \\
\hline Residual & 783.21 & 12 & 65.27 & & & \\
\hline Lack of fit & 772.12 & 10 & 77.21 & 13.93 & 0.0688 & NS \\
\hline Pure error & 11.09 & 2 & 5.54 & & & \\
\hline Cor total & 9712.54 & 26 & & & & \\
\hline
\end{tabular}

design. The obtain the 'goodness of fit', ANOVA was used to analyze the data from this study. The COD removal model was significant by the $F$-test at the 95\% confidence level ( $\mathrm{prob}>F<0.05$ ) [25]. The results of the ANOVA of the regression parameters of the predicted response surface quadratic models for COD removal efficiency, with insignificant model terms excluded, are shown in Table 3. The relationships between COD removal efficiency and the four operating parameters (i.e. current density, inter-electrode gap, $\mathrm{pH}$ and operation time) were fitted to the second-order polynomial. The Equation (3) is as follows:

$$
\begin{aligned}
Y & =85.43+5.34 X_{1}+12.17 X_{2}-7.52 X_{3}+9.89 X_{4}+8.89 X_{1} X_{2} \\
& -4.01 X_{1} X_{3}+3.34 X_{1} X_{4}-10.89 X_{2} X_{3}-11.54 X_{2} X_{4} \\
& +0.44 X_{3} X_{4}-7.13 X_{1}^{2}-16.43 X_{2}^{2}-22.79 X_{3}^{2}-3.28 X_{4}^{2}
\end{aligned}
$$

...where $Y$ is the COD removal efficiency (\%); $X_{1}, X_{2}$, $X_{3}$ and $X_{4}$ denote the coded values for current density $\left(\mathrm{mA} / \mathrm{cm}^{2}\right)$, inter-electrode gap $(\mathrm{cm}), \mathrm{pH}$ and reaction time $(\mathrm{h})$, respectively.

In Table 3, the model $F$-value of 9.77 implies the model is significant. There is only a $0.02 \%$ chance that a "model $F$-value" this large could occur due to noise. Value of "Prob $>F$ " less than 0.05 indicate model terms are significant. In this case $X_{1}, X_{2}, X_{3}, X_{4}, X_{1} X_{2}, X_{2} X_{3}$, $X_{2} X_{4}, X_{2}^{2}, X_{3}^{2}$ are significant model terms. The "Lack of Fit $F$-value" of 13.93 implies there is a $6.88 \%$ chance that a "Lack of Fit $F$-value" this large could occur due to noise.

Fig. 5 shows the normal probability of COD removal efficiency of $t$-test residual, and the figure

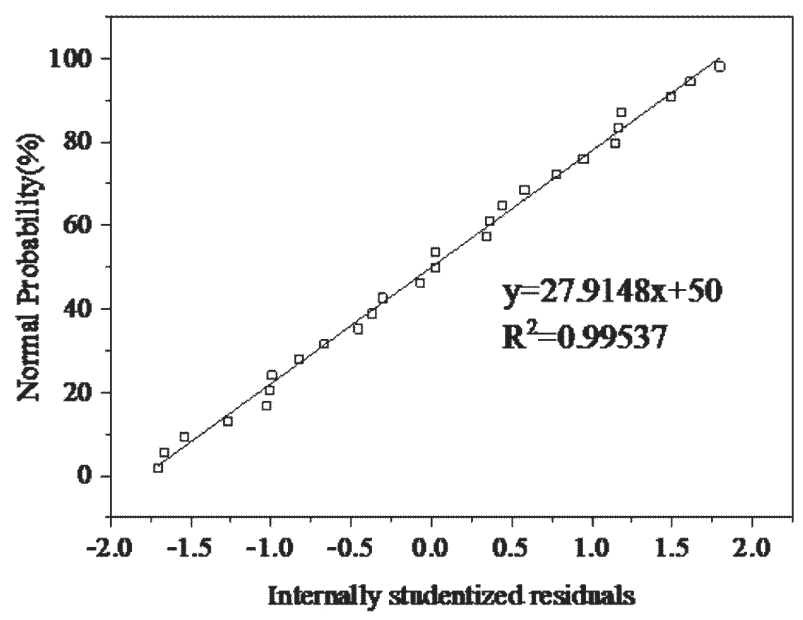

Fig. 5. Normal probability plot of the internally studentised residuals in the response surface model. 
is an important diagnostic tool to check whether the model is sufficient. Most of the obtained data points followed a straight line, suggesting that the data were normally distributed in the responses of the model. The determination coefficient $R^{2}$ was 0.9954 , which indicated the ratio of prediction variables. The value of $\mathrm{R}^{2}$ was high, implying that the predicted value of response was not different from the actual value. The regression model of the adjusted decision coefficient $\left(R_{\text {adj }}{ }^{2}=0.9253\right)$ was close to 1 , which indicated that the experimental value could be significantly predicted.

\section{Interactive Effects Analysis and Optimization}

Contour plots of the mathematical regression model were described using Design Expert software to study the interactive relationship between independent variables and response. Fig. 6 (a-f) show the contour plots. Three variables were varied within the experimental range, whilst the other variables were maintained constant.

Fig. 6a) describes the interaction between the current density and inter-electrode gap. When the current

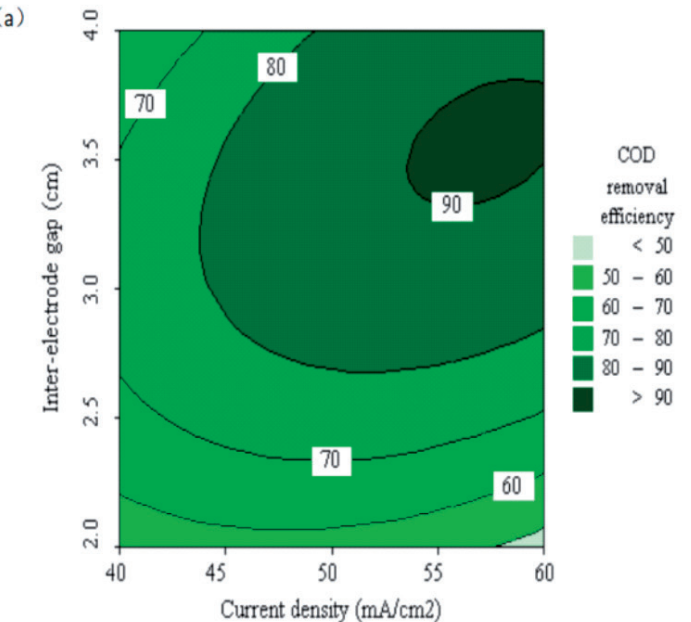

(c)
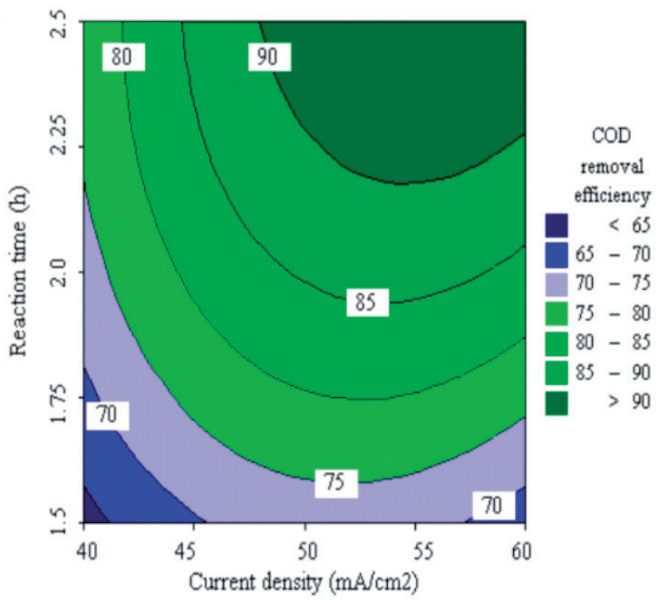

(e)

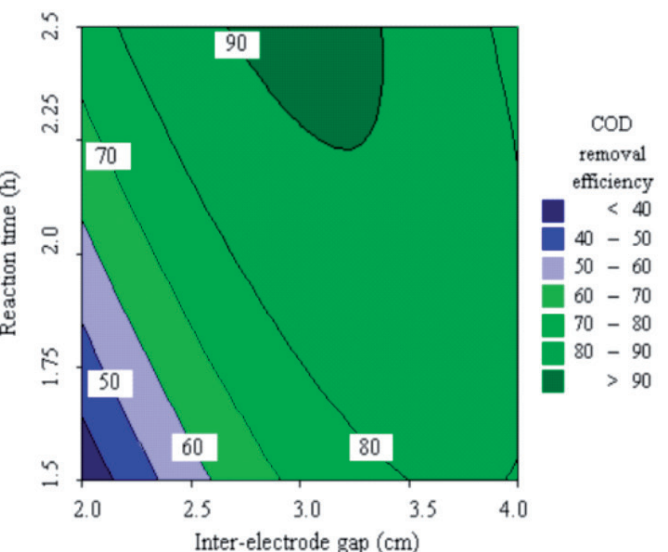

(b)

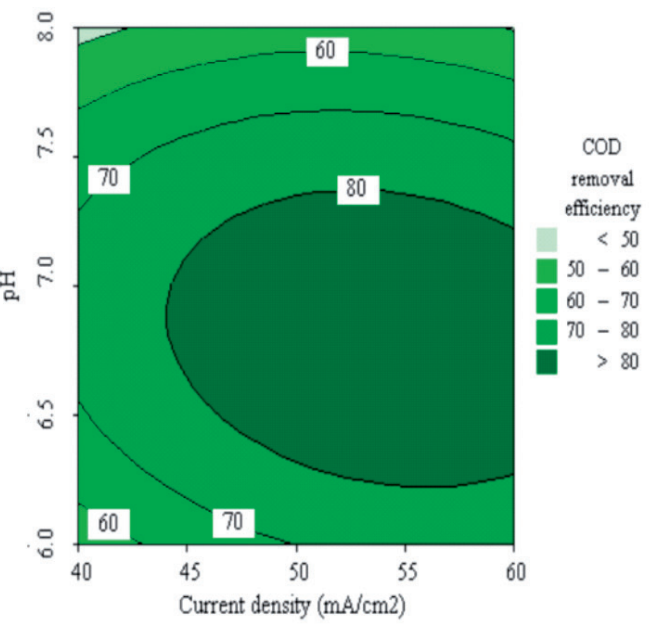

(d)
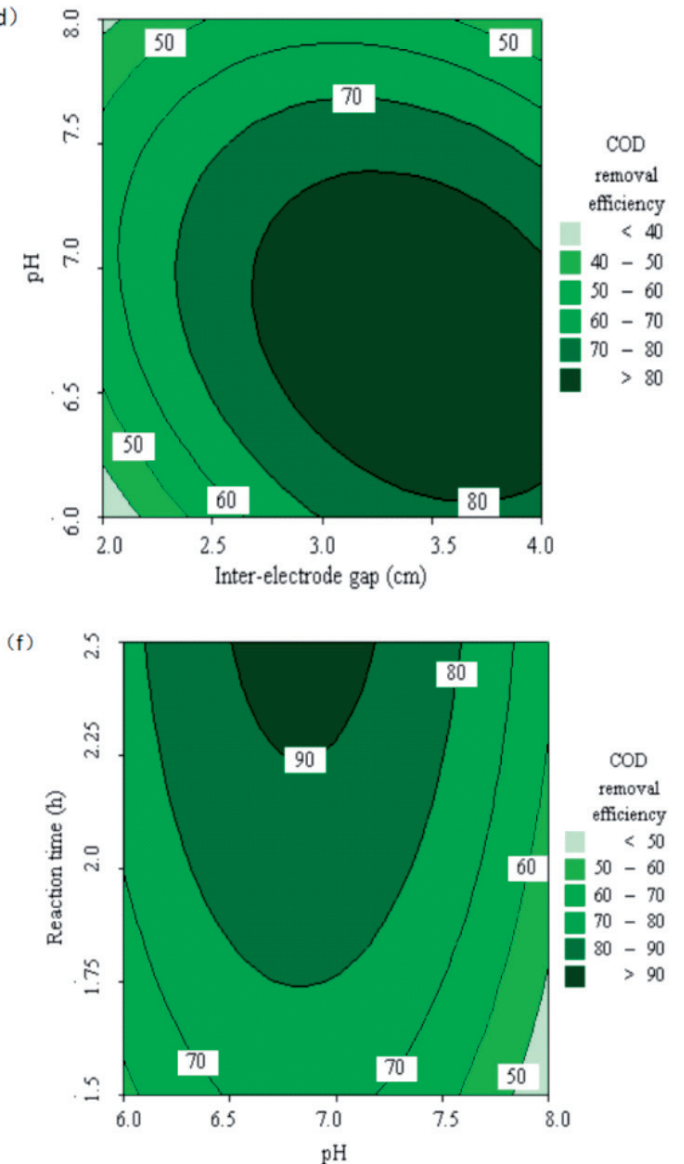

Fig. 6. Response surface plots of interactive effect among factors on (a-f) COD reduction efficiency (\%). 
Table 4. Verification test of the fitting models.

\begin{tabular}{|c|c|c|c|c|c|c|c|}
\hline \multirow{2}{*}{ Test number } & \multicolumn{4}{|c|}{ Operation parameters } & \multicolumn{3}{c|}{ Response value $Y(\%)$} \\
\cline { 2 - 8 } & $X_{1}$ & $X_{2}$ & $X_{3}$ & $X_{4}$ & Observed value & Predicted value & Error \\
\hline 1 & -0.36 & -0.049 & 0.43 & -0.049 & 75.08 & 76.16 & -1.44 \\
\hline 2 & 0.85 & 0.71 & 0.085 & 0.48 & 90.28 & 90.01 & 0.30 \\
\hline 3 & 0.25 & -0.91 & 0.45 & -0.73 & 38.56 & 38.22 & 0.88 \\
\hline 4 & 0.34 & -0.23 & -0.14 & -0.76 & 70.29 & 69.73 & 0.80 \\
\hline 5 & -0.97 & -0.46 & 0.41 & -0.41 & 59.65 & 59.23 & 0.70 \\
\hline
\end{tabular}

density was $40 \mathrm{~mA} / \mathrm{cm}^{2}$, the COD removal efficiency increased from $53.7 \%$ to $73.2 \%$ and then gradually decreased to $60.1 \%$ with the increase in plate spacing from $2 \mathrm{~cm}$ to $4 \mathrm{~cm}$. When the current density was $60 \mathrm{~mA} / \mathrm{cm}^{2}$, the COD removal efficiency increased from $46.6 \%$ to $90.4 \%$ and then decreased to $88.4 \%$ with the increase in electrode plate spacing from $2 \mathrm{~cm}$ to $4 \mathrm{~cm}$.

The interaction between current density and $\mathrm{pH}$ is illustrated in Fig. 6b). When the current density was $40 \mathrm{~mA} / \mathrm{cm}^{2}$, the $\mathrm{pH}$ increased from 6 to 8 . The plot shows that the COD removal efficiency increased by $19.2 \%$ (from $54.2 \%$ to $73.4 \%$ ) and then decreased by $26.3 \%$ (from $73.4 \%$ to $47.1 \%$ ). At the current density of $60 \mathrm{~mA} / \mathrm{cm}^{2}$, the COD removal efficiency increased by $12.5 \%$ (from $72.7 \%$ to $85.2 \%$ ) and then decreased by $35.5 \%$ (from $85.2 \%$ to $49.7 \%$ ) when the $\mathrm{pH}$ increased from 6 to 8 .

Fig. 6c) describes the interaction between current density and reaction time. At the reaction time of $1.5 \mathrm{~h}$, the removal efficiency increased by $9.2 \%$ (from $63.3 \%$ to $72.5 \%$ ) and then decreased by $5.1 \%$ (from $72.5 \%$ to $67.4 \%$ ) when the current density increased from $40 \mathrm{~mA} / \mathrm{cm}^{2}$ to $60 \mathrm{~mA} / \mathrm{cm}^{2}$. At the reaction time of $2.5 \mathrm{~h}$, the removal efficiency increased by $18.4 \%$ (from $76.3 \%$ to $94.7 \%$ ) and then decreased by $1.0 \%$ (from $94.7 \%$ to $93.7 \%$ ) when the current density increased from $40 \mathrm{~mA} / \mathrm{cm}^{2}$ to $60 \mathrm{~mA} / \mathrm{cm}^{2}$.

Fig. 6d) describes the interaction between interelectrode gap and $\mathrm{pH}$. At the inter-electrode gap of $2 \mathrm{~cm}$, the removal efficiency increased by $25.7 \%$ (from $31.4 \%$ to $57.1 \%$ ) and then decreased by $19.2 \%$ (from $57.1 \%$ to $37.9 \%$ ) when the $\mathrm{pH}$ increased from 6 to 8 . At the inter-electrode gap of $4 \mathrm{~cm}$, the removal efficiency increased by $8.2 \%$ (from $77.0 \%$ to $85.2 \%$ ) and then decreased by $44.7 \%$ (from $85.2 \%$ to $40.5 \%$ ) when the $\mathrm{pH}$ increased from 6 to 8 .

The interaction between reaction time and interelectrode gap is illustrated in Fig. 6e). When the reaction time was $1.5 \mathrm{~h}$, the inter-electrode gap increased from $2 \mathrm{~cm}$ to $4 \mathrm{~cm}$. The plot shows that the COD removal efficiency increased by $48.2 \%$ (from $32.7 \%$ to $80.9 \%$ ) and then decreased by $1.2 \%$ (from $80.9 \%$ to $79.7 \%$ ). At the reaction time of $2.5 \mathrm{~h}$, the COD removal efficiency increased by $17.0 \%$ (from $75.0 \%$ to $92.0 \%$ ) and then decreased by $15.5 \%$ (from $92.0 \%$ to $76.5 \%$ ) when the inter-electrode gap increased from 2 to $4 \mathrm{~cm}$.
Fig. 6f) describes the interaction between reaction time and $\mathrm{pH}$. At the reaction time of $1.5 \mathrm{~h}$, the COD removal efficiency increased by $15.3 \%$ (from $57.8 \%$ to $73.1 \%$ ) and then decreased by $30.9 \%$ (from $73.1 \%$ to $42.2 \%$ ) when the $\mathrm{pH}$ increased from 6 to 8 . At the reaction time of $2.5 \mathrm{~h}$, the COD removal efficiency increased by $16.0 \%$ (from $76.6 \%$ to $92.6 \%$ ) and then decreased by $29.9 \%$ (from $92.6 \%$ to $62.7 \%$ ) when the $\mathrm{pH}$ increased from 6 to 8 .

\section{Optimisation and Validation Experiment}

The desirable point prediction function in the experimental design was applied to identify the optimum conditions to maximise COD removal efficiency within the studied experimental ranges. The optimal results for COD reduction were predicted to occur under the following conditions: a current density of $58.8 \mathrm{~mA} / \mathrm{cm}^{2}$, an inter-electrode gap of $3 \mathrm{~cm}, \mathrm{pH}$ of 6.73 and reaction time of $2.23 \mathrm{~h}$. The actual value of COD removal efficiency was $92.70 \%$, Compared with the team degradation of PAM by electro flocculation of aluminum plate, the COD removal efficiency is $90.9 \%$ after optimization of response parameters [12]. The degradation effect of Ir-Ta electrode is better, which was in good agreement with the predicted value of $92.24 \%$ from the regression model, with small error. To confirm the predicted results, experiments were conducted using the optimum conditions that were given by the optimisation software. The COD removal efficiency is described in Table 4. The experimental results were close to the predicted values but with a lower percentage of error $(-1.44,0.30,0.88,0.80,0.70)$.

\section{Conclusions}

The effects of current density, plate spacing, initial $\mathrm{pH}$ and reaction time on the removal rate of PAM were studied. RSM was used to optimize the experimental parameters. Regression analysis showed that the experimental data fitted well with the second-order polynomial model. The coefficient of determination $R^{2}$ was $0.9954, F$-value was 9.77 , and the curve model was significant. When the current density was $58.80 \mathrm{~mA} / \mathrm{cm}^{2}$, the electrode plate spacing was $3.07 \mathrm{~cm}$, 
the initial $\mathrm{pH}$ of the solution was 6.73 , and the reaction time was $2.23 \mathrm{~h}$. The COD removal rate reached $92.70 \%$. In accordance with the analysis of variance, $p$-values of current density $\left(X_{1}\right)$, plate spacing $\left(X_{2}\right), \mathrm{pH}\left(X_{3}\right)$ and reaction time $\left(X_{4}\right)$ were less than 0.05 , implying that they were significant factors. The interaction between current density and inter-electrode, inter-electrode and $\mathrm{pH}$, inter-electrode and reaction time significantly affected the COD removal efficiency. The successful application of the BBD design experiment showed that the electrocatalytic technology can effectively degrade PAM in wastewater.

\section{Acknowledgments}

The authors are grateful for financial support from the Scientific Research Foundation of Educational Commission of Hubei Province, China (Q20201315).

\section{Conflict of Interest}

The authors declare no conflict of interest.

\section{References}

1. ZHU D.W., ZHANG J.C., HAN Y.G., WANG H.G., FENG Y.J. Laboratory Study on the Potential EOR Use of HPAM/ VES Hybrid in High-Temperature and High-Salinity Oil Reservoirs. Journal of Chemistry, 2013 (927519), 2013.

2. WANG F., LÜ H.M., WANG X.J., JING B., DUAN M., XIONG Y., FANG S.W. Preparation of a selective flocculant for treatment of oily wastewater produced from polymer flooding and its flocculant mechanism. Water Science and Technology, 79 (9), 1648, 2019.

3. XIONG B.Y., LOSS R.D., SHIELDS D., PAWLIK T., HOCHREITER R., ZYDNEY A.L., KUMAR M. Polyacrylamide degradation and its implications in environmental systems. NPJ Clean Water, 1 (1), 1, 2018.

4. BAO M.T., CHEN Q.G., LI Y.M., JIANG G.C. Biodegradation of partially hydrolyzed polyacrylamide by bacteria isolated from production water after polymer flooding in an oil field. Journal of Hazardous Materials, 184 (1-3), 105, 2010.

5. ZHU M.J., YAO J., QIN Z.H., LIAN L.N., ZHANG C. Response surface methodology approach for the optimisation of adsorption of hydrolysed polyacrylamide from polymer-flooding wastewater onto steel slag: a good option of waste mitigation. Water Science and Technology, 76 (4), 776, 2017.

6. ZHANG C.C., ZHAO L.M., BAO M.T., LU J.R. Potential of hydrolyzed polyacrylamide biodegradation to final products through regulating its own nitrogen transformation in different dissolved oxygen systems. Bioresource Technology, 256, 61, 2018.

7. ZHAO L.M., BAO M.T., YAN M., LU J.R. Kinetics and thermodynamics of biodegradation of hydrolyzed polyacrylamide under anaerobic and aerobic conditions. Bioresource Technology, 216, 95, 2016.

8. AKBAR M., KHAN M.F.S., QIAN L., WANG H. Degradation of Polyacrylamide (PAM) and methane production by mesophilic and thermophilic anaerobic digestion: Effect of temperature and concentration. Frontiers of Environmental Science \& Engineering, 14 (6), $1,2020$.

9. ZHANG S.T., HAN Y.H., ZHANG X.F., WU C.T., AN Y. Optimization of the conditions for degradation of hydrolyzed polyacrylamide using electro-coagulation. Desalination and Water Treatment, 179, 148, 2020.

10. HE Q.B., DENG C., XU Y., SHEN D., DONG B., DAI X.H. Optimization of and mechanism for the coagulationflocculation of oil-field wastewater from polymer flooding. Desalination and Water Treatment, 57 (50), 23709, 2016.

11. PI Y.R., ZHENG Z.H., BAO M.T., LI Y.M., ZHOU Y.Y., SANG G.L. Treatment of partially hydrolyzed polyacrylamide wastewater by combined Fenton oxidation and anaerobic biological processes. Chemical Engineering Journal, 273, 1, 2015.

12. ZHU M.J., YAO J., WANG W.B., YIN X.Q., CHEN W., WU X.Y. Using response surface methodology to evaluate electrocoagulation in the pretreatment of produced water from polymer-flooding well of Dagang Oilfield with bipolar aluminum electrodes. Desalination and Water Treatment, 57 (33), 15314, 2016.

13. GAO J., ZHAO H.H., JIAO W.Z., LIU Y.Z., ZHANG D.M., CHEN L.J. Enhanced electro-catalytic degradation and kinetics of phenol in wastewater by high-gravity field with $\mathrm{Ti} / \mathrm{RuO}_{2}-\mathrm{IrO}_{2}-\mathrm{SnO}_{2}$ anodes. Desalination and Water Treatment, 168, 100, 2019.

14. ABDELHAY A., JUM'H I., ALBSOUL A., ABU ARIDEH. D., QATANANI B. Performance of electrochemical oxidation over BDD anode for the treatment of different industrial dye-containing wastewater effluents. Water Reuse, 11 (1), 110, 2021.

15. LUO J.K., ZHANG H., LI Z.H. Highly efficient degradation of phenol from wastewater via an electrocatalytic oxidation approach with a $\mathrm{CeO}_{2}-\mathrm{CuO}$ cathode. RSC Advances, 8(27), 15167, 2018.

16. ANSARI A., NEMATOLLAHI D. Convergent paired electrocatalytic degradation of $\mathrm{p}$-dinitrobenzene by $\mathrm{Ti} / \mathrm{SnO}_{2}-\mathrm{Sb} / \mathrm{\beta}_{-} \mathrm{PbO}_{2}$ anode. $\mathrm{A}$ new insight into the electrochemical degradation mechanism. Applied Catalysis B-Environmental, 261, 118226, 2020.

17. YANG L.J., LI Y.Y., TIAN M., WANG J., GUI H.H. Degradation of Polyacrylamide in Oil Wastewater by Electrocatalytic Oxidation. Advanced Materials Research, 581-582:64, 2012.

18. MARAN J.P., MANIKANDAN S., MEKALA V. Modeling and optimization of betalain extraction from Opuntia ficus-indica using Box-Behnken design with desirability function. Industrial Crops and Products, 49, 304, 2013.

19. BEZERRA C.W.D., SANTOS G.D.S., PUPO M.M.D., GOMES M.D., DA SILVA R.S., EGUILUZ K.I.B., SALAZAR-BANDA G.R.Novel eco-friendly method to prepare $\mathrm{Ti} / \mathrm{RuO}_{2}-\mathrm{IrO}_{2}$ anodes by using polyvinyl alcohol as the solvent. Journal of Electroanalytical Chemistry, 859, 113822, 2020.

20. HWANG H., LIM D., KIM T., LEE D., SHIM S.E., BAECK S.H. Electro-Catalytic Activity of $\mathrm{RuO}_{2}-\mathrm{IrO}_{2}-$ $\mathrm{Ta}_{2} \mathrm{O}_{5}$ Mixed Metal Oxide Prepared by Spray Thermal Decomposition for Alkaline Water Electrolysis. Journal of Nanoscience \& Nanotechnology, 16 (5), 4405, 2016.

21. LIN H., NIU J.F., DING S.Y., ZHANG L.L. Electrochemical degradation of perfluorooctanoic acid (PFOA) by $\mathrm{Ti} / \mathrm{SnO}_{2}-\mathrm{Sb}$, Ti $/ \mathrm{SnO}_{2}-\mathrm{Sb} / \mathrm{PbO}_{2}$ and $\mathrm{Ti} / \mathrm{SnO}_{2}-\mathrm{Sb} /$ $\mathrm{MnO}_{2}$ anodes. Water Research, 46 (7), 2281, 2012. 
22. ABDELHAY A., JUM'H I., ABDULHAY E., ALKAZWINI A., ALZUBI M. Anodic oxidation of slaughterhouse wastewater on boron doped diamond: process variables effect. Water Science and Technology, 76 (12), 3227, 2017.

23. HAN Y.H., ZHANG S.T., ZHANG X.F., CHEN J.Q. Electrochemical oxidation of of Hydrolyzed Polyacrylamide (HPAM) at $\mathrm{Ti} / \mathrm{SnO}_{2}-\mathrm{Sb}_{2} \mathrm{O}_{3} / \beta-\mathrm{PbO}_{2}$ Anode. Degradation Kinetics and Mechanisms. International Journal of Electrochemical science, 15 (4), 3382, 2020.

24. LI H., KUANG X.M., QIU C.P., SHEN X.L., ZHANG B.T., HUA L. Advanced electrochemical treatment of real biotreated petrochemical wastewater by boron doped diamond anode: performance, kinetics, and degradation mechanism. Water Science \& Technology, 82 (4), 773, 2020.

25. ZHU M.J., YIN X.Q., LIU Q., FENG Z.Y. Optimization and Modelling Using the Response Surface Methodology for Methylene Blue Removal by Electrocoagulation/ Hazelnut Shell Adsorption Coupling in a Batch System. Polish Journal of Environmental Studies, 29 (3), 2493, 2020. 